\title{
1. Introduction: Is scholarship in crisis?
}

Our first priority must be a reorientation of social science research from the omnipresent requirement to continuously publish in "high-quality journals" to

the overriding goal and purpose of creating original knowledge that matters to society. (Alvesson, Gabriel, and Paulsen, 2017: 85)

Is there a crisis in academic research? A growing number of voices are echoing a concern for the future of academia and our scholarly profession. This seems to be a worry in most disciplines, but my personal experiences come mostly from management scholarship. Management research has been subject to critical attention during recent years. There have been calls for redirection toward what matters most, and toward scholarship with an impact. In this book, I suggest a way forward.

\section{CRISIS IN SCHOLARSHIP}

The conduct of management research is the subject of increasing criticism from several perspectives and sources (Aguinis et al., 2014; Honig et al., 2017; Pettigrew, 2011; Tsui, 2013). The criticism is related to various aspects of our research institutions, message, audience, channels, and community, as well as to concerns about the future of our scholarly identity. Its importance has been addressed in recent keynote presentations at main management conferences such as, for example, the 2018 conference of the Academy of Management (AOM), the 2017 and 2019 conferences of the European Academy of Management (EURAM), and the 2017 conference of the European Group for Organizational Studies (EGOS). We have also recently seen how these issues are being addressed by movements such as the San Francisco Declaration on Research Assessment (DORA) and Responsible Research in Business and Management (RRBM), as well as national research evaluation initiatives. 
I will start this book with some reflections about scholarship and what good scholarship is. My academic background is in the AOM. North American thinking about good scholarship has thus influenced me. However, I have lived and worked in Europe all my life, and during the period 2010-12, I was President of EURAM. Reflections from these experiences have urged me to write this book, and I present some here.

For several years I have listened to the criticism and concerns raised by Andrew Pettigrew and Mats Alvesson. Their many contributions have also stimulated me to raise my voice on the topic, and a few years ago my thinking was sharpened as I applied for a European Research Council (ERC) Advanced Grant. The ERC defined research excellence in terms of groundbreaking, creative and independent achievements beyond the state of the art; innovation potential; sound leadership in training and advancing young scientists; and work that has second and third-order impacts. I brought these concepts with me when writing this book.

In a long series of publications, Pettigrew and Alvesson have raised concerns regarding our profession as management scholars, and that we as management scholars are meeting neither rigor nor relevance criteria. They argue that our research often lacks meaning, reflection, and impact. Furthermore, Alvesson and Pettigrew have both discussed the future of business schools. In a recent book, Alvesson et al. (2017) search for meaning in our research, and describe the present publishing system in critical terms. They argue that research publications are escalating, but the research contains less and less meaning. Scholars are becoming publishing technicians. Alvesson et al. make distinctions among problem definitions and solutions at individual, institutional, and policy levels. They do not present one main solution or one way of solving everything, but rather offer many small messages that they argue can contribute to giving meaning. Their first point is, however, "reorientation of social science research from the omnipresent requirement to continuously publish in 'high-quality journals' to the overriding goal and purpose of creating original knowledge that matters to society" (2017: 85).

\section{ATTACKS ON OUR SCHOLARLY ECOSYSTEM}

Research should contribute to the accumulation and dissemination of knowledge to all of society. The ultimate objective should be to come up with a breakthrough that changes our lives for the better (Moosa, 2018: 173). This ideal is under attack, as is the role of our institutions, our message, our community, our channels, and our audience. These issues 
are all important for developing a sustainable scholarly ecosystem. An ecosystem is a concept developed to secure sustainability, and in this book I will introduce the elements in a scholarly sustainable ecosystem. The main elements in my presentation are institutions, message, audience, channels, and community. I will argue that this system may help us analyze our present status and contribute to achieving sustainability. This ecosystem may help us understand where we are today, and help us toward true and sustainable scholarship. The book is knitted around these ecosystem elements and relationships.

My main experiences are within business schools, and particularly in the field of management. Business schools face pressures that seem particularly acute (Hall and Martin, 2019). They are not necessarily more disposed to misconduct, but competitive pressure may be greater on business schools and their faculty than in many other areas. Rewards for publishing in elite journals are often more lucrative, and the research findings in business may not, in the short run, do any direct harm to business.

What is our message? Our view of scholarship has narrowed over time. Quality is today measured in terms of where and at what pace scholars are getting their work published, rather than in terms of the impact of their work. What is true scholarship? Boyer (1990) offers a benchmark reflection about what true scholarship is. Scholars are academics who conduct research, publish, and then perhaps convey their knowledge to students or apply what they have learned (Boyer, 1990: 15). Boyer argues that the functions of scholarship dynamically interact and form an interdependent whole (1990: 25).

A neoliberal market ideology is entering academia (Moosa, 2018). ${ }^{1}$ This ideology has a focus on extrinsic monetary incentives and self-reliance. This has consequences for definitions of academic careers and what is needed to achieve them. The criteria for academic careers are vulnerable to globalization and international employment patterns. But what do we know about what constitutes a sustainable scholarly community? What does it mean to make an academic career? What types of academic careers do we have? How do we become a part of a scholarly community, and how do we serve it? My message in this book is that we need to go beyond a "publish or perish" (POP) oriented, "winner takes all" culture. 
There is strong concern about the way we communicate our research, particularly with regard to channels. All over the world today, in every academic discipline, there is concern about a decline in the average quality of articles published in academic journals (Scott, 2019). A larger share of university and business school professors must publish to meet the survival demands of their institutions. There has thus been an increasing demand for journals in which to publish. Alvesson et al. (2017) paint a critical picture of the present academic publishing game, and present proposals and suggestions for recovering meaning in our publications. Strong concern is thus also raised about scientific misconduct in management research (Honig and Lampel, 2018; Tourish, 2019). We are experiencing an audit and surveillance culture with negative consequences (Walsh, 2011).

Research is often seen as a self-referential inward-looking system. It is often incremental and gap spotting. It is not heavily influenced by expectations of society and media, politics and business; and theory and practice are not connected. I take the position that our research should be addressed to a large set of stakeholders, and not only to a narrow set in academia.

Chapter 2 sets out the POP culture, Boyer's work on true scholarship, and the scholarly ecosystem.

\section{ORGANIZATIONAL DEBATES AND INITIATIVES TO RESOLVING THE CRISIS}

The crisis in scholarship is escalating and new, and more, actors are taking initiatives to fight this crisis and to find alternatives. For several decades, the AOM has been a leading international actor in promoting and supporting scholarship, including developing a vibrant community of scholars. The AOM has its roots in North America. It has been criticized for spreading destructive norms, but has also been a victim of larger movements. This is displayed in the reflections of many of their outgoing presidents, which have been published in the Academy of Management Review (AMR) since the mid-1990s The AOM presidents and the Academy's governance bodies have seen the challenges developing, but they have been like captains on a large tankship. It has been very difficult to make fast changes and to maneuver in turbulent waters away from the home ports. Reflections from the captains - the outgoing presidents of $\mathrm{AOM}$ - are presented in Chapter 3. 
Many boats, or scholarly communities, have followed in the wake of AOM, but some have taken initiatives - either alone or together with AOM - to change the direction of the scholarly community. During my EURAM presidency in 2010-12, I had the ambition of presenting EURAM as a tugboat, supporting AOM in its navigation-including contributing with local knowledge and experiences. For this reason, we in EURAM institutionalized meetings among presidents of various associations of management. My EURAM experiences are presented in Chapter 4. EURAM is not the only association rendering resources to redirect the development of management research and scholarshipsthere exist several other tugboats. The British Academy of Management (BAM) has raised its voice in relation to national research assessments, several journal editors have devoted space to addressing problems in management research, and associations such as DORA and RRBM are developing to challenge topics such as the use of metrics and the lack of relevance.

The Research Evaluation Framework (REF) in the UK is a process of expert review, including assessment of outputs, impacts beyond academia, and the environment that supports research. The REF's objective is to provide a yardstick for allocation of funds. It shall provide accountability for public investment in research and produce evidence of the benefits of this investment. DORA contains a criticism of metrics-driven research evaluations. The DORA declaration requests that less emphasis is placed on publication metrics and nonarticle output is given greater inclusion. RRBM is dedicated to inspiring, encouraging, and supporting credible and useful research in the business and management disciplines. It is a virtual organization initially developed by leading management scholars from various countries. There are in addition many individual initiatives and contributions. The above mentioned initiatives will be presented in Chapter 5 .

\section{A SHARING PHILOSOPHY}

My objective with this book is to contribute to creating a new game for research, not simply changing the rules of an existing one. As President of EURAM, I wanted to create a community of engaged management scholars (Huse, 2010). In this book, I will follow the call of several of the outgoing AOM presidents, for example van de Ven (2002), and present a "sharing" philosophy of management research. My motivation is aligned with the arguments by previous AOM presidents Jean Bartunek, Andrew 
van de Ven, and David Whetten that (a) a communal, (b) an open source/ innovation, and (c) an impact-driven research philosophy will advance the scholarship of management and may solve problems today being experienced in management research.

The sharing philosophy builds on concepts such as:

- A communal approach, including communal and joint credit; giving credit for research and not only for publications; communities of engaged scholars.

- An open source/innovation approach, including open sources for research, learning and innovation; leadership and liaising; venturesome research designs; holistic engagement and appreciation of diversity; appreciating impact in academia, business, and society.

- An impact-driven approach, including evaluating research and impact on a long-term basis; appreciated in both academia and practice; development of junior scholars; multiplicative behavioral processes.

I will try to use my experiences from various settings to present and illustrate this sharing philosophy. In Chapter 6, I will present experiences from the Norefjell workshops to illustrate the communal approach, programmatic research, and the development of "value creating board" research as a distinct research stream. In Chapter 7, I will present a lighthouse university. Witten/Herdecke University in Germany is an anthroposophical inspired private university where I spent a five-year late career period. Core lessons from Witten were open innovation and open sharing, passion and compassion, and thinking holistically, including coming close to some of our society's grand challenges. The impact-driven approach is the core of Chapter 8. It is about socially committed scholarship, longitudinal research with stakeholders, and polymorphic research.

Chapter 9 contains reflections and a discussion of how an ecosystem thinking may contribute to a move from a destructive POP culture to a culture based on true scholarship. I summarize and raise challenges on issues laid out throughout the book: what scholars are, and the scholarly life cycle; that we need more than one boat to get to true scholarship; and that we need lighthouses to help us navigate. In the final chapter, I summarize and conclude with regard to the sharing philosophy and our scholarly ecosystem. I present ways to resolve the crisis in research. Senior scholars should devote time to developing the scholarly community; scholarly associations should appreciate context-specific charges and 
needs; and thus we shall all stand up as lighthouses in leading academia back to true scholarship.

I wanted to write a personal book. It is provocative, and I attack the present POP culture. I want to contribute to true scholarship and a sustainable society. Across the pages, I contribute to resolving the urgent need to recover meaning in our research, and through my examples I sort and put flesh on many of the initiatives taken. In this book, I am returning to the past to create a new game for the future. 